\title{
Adverse effects of caffeinated energy drinks among youth and young adults in Canada: a Web-based survey
}

\author{
David Hammond PhD, Jessica L. Reid MSc, Sara Zukowski BSc
}

\section{Abstract}

Background: Energy drink consumption has increased dramatically among young Canadians, with anecdotal evidence of adverse health effects. There is a lack of population-based studies to examine the prevalence of adverse events from energy drinks, particularly among young people. The current study sought to assess adverse events from energy drinks among a population-based sample of youth and young adults in Canada.

Methods: An online survey was conducted in 2015 with a national sample of youth (aged 12-17 yr) and young adults (aged 18-24 yr) recruited from a consumer panel. Respondents reported prior consumption of energy drinks as well as adverse outcomes, concurrent activities associated with the outcomes and whether medical attention was sought or considered. Adverse events from coffee were also assessed for comparison. Weighted analyses are reported.

Results: Of the 2055 respondents, 1516 (73.8\%) reported having ever consumed an energy drink, and 1741 (84.7\%) reported having ever consumed coffee (unweighted). Overall, $55.4 \%$ of respondents who had ever consumed an energy drink reported that they had experienced at least 1 adverse event, including fast heartbeat (24.7\%), difficulty sleeping (24.1\%), headache (18.3\%), nausea/ vomiting/diarrhea $(5.1 \%)$, chest pain $(3.6 \%)$ and seizures $(0.2 \%) ; 3.1 \%$ had sought or had considered seeking medical help for an adverse event. The prevalence of reported adverse events was significantly greater among energy drink consumers than among coffee consumers (36.0\%) (odds ratio [OR] 2.67 [95\% confidence interval (Cl) 2.01-2.56]), as was the proportion who reported seeking or considering seeking medical help for adverse events (3.1\% v. 1.4\%) (OR 2.18 [95\% Cl 1.39-3.41]).

Interpretation: More than half of youth and young adults who had consumed energy drinks reported adverse outcomes, some serious enough to warrant seeking medical help. The adverse outcomes were consistent with the physiologic effects of caffeine but were significantly more prevalent than with other sources of caffeine such as coffee, consistent with data from national adverse event databases.

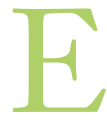
nergy drinks are beverages that contain concentrated amounts of caffeine and other stimulants, including sugars, vitamins, amino acids such as taurine and various herbal supplements. ${ }^{1}$ The recent dramatic increase in the consumption of energy drinks has led to concerns about their health impact..$^{2-4}$ For example, Health Canada's Expert Panel on Caffeinated Energy Drinks labelled energy drinks as "stimulant drug containing drinks" and identified them as a "safety concern" in 2010.5 Health concerns have primarily focused on potential risks to children and youth, given their greater susceptibility to the effects of caffeine and other stimulants. ${ }^{6-9}$ The adverse effects of caffeine include anxiety, headache and insomnia. ${ }^{6,8}$ More serious adverse effects from excessive caffeine consumption although rare - can include vomiting and abdominal pain, hypokalemia, hallucinations, seizures, arrhythmias and even death. ${ }^{6}$ Concerns about caffeine consumption among young people have prompted Health Canada to issue recommended maximum daily caffeine intake levels for children less than 13 years of age (for those aged $10-12 \mathrm{yr}, 85 \mathrm{mg}$, roughly equivalent to $1250-\mathrm{mL}$ can of Red Bull [Red Bull $\mathrm{GmbH}]$; for adolescents aged $\geq 13 \mathrm{yr}$, no more than $2.5 \mathrm{mg}$

Competing interests: None declared.

This article has been peer reviewed.

Correspondence to: David Hammond, dhammond@uwaterloo.ca CMAJ Open 2018. DOI:10.9778/cmajo.20160154 
per kilogram of body weight). ${ }^{7}$ Energy drinks contain stimulants other than caffeine that may have independent physiologic effects or may interact with caffeine in ways that are poorly understood.

Evidence on adverse events is a priority given changes to the regulatory status of energy drinks in Canada. Before 2013, energy drinks were classified as a Natural Health Product; however, in 2013, they were reclassified to fall under the Food and Drug Act and became subject to new regulations on caffeine content, mandatory cautionary labelling and restrictions on health claims. ${ }^{10}$ As part of this transition, Health Canada has committed to monitoring the safety of energy drinks in order to evaluate the effectiveness of these new measures and to review the "temporary market authorization" provided to energy drinks.

The energy drink industry has maintained the safety of energy drink consumption. ${ }^{11,12}$ Expert panels, medical associations and regulatory agencies, however, have continued to note their concern about adverse effects among young people., ${ }^{3,13,14}$ Data on the adverse effects of energy drink consumption derive from a variety of sources, including clinical trials, case reports, data on emergency department visits and calls to poison centres. ${ }^{15,16}$ Most reports are of short-term effects. For example, trials have shown acute cardiovascular effects of energy drinks, particularly among those at higher risk for such events. ${ }^{17,18}$ Case reports have linked energy drink consumption with serious adverse events, such as stroke, ${ }^{19}$ seizures ${ }^{20-22}$ and serious cardiac effects. ${ }^{23-27}$ Data from emergency department visits have also identified adverse outcomes associated with energy drinks. ${ }^{28-31}$ For example, an analysis of national US data showed that the number of emergency department visits linked with energy drinks doubled between $2007(n=$ $10068)$ and $2011(n=20783) . .^{32}$ An analysis of calls to the US National Poison Data System in a 12 -month period in 2010/11 identified 4854 calls related to energy drinks, including 1480 calls that were not also related to alcohol; $15 \%$ were considered to be "moderate to major" adverse effects. ${ }^{33}$ Similarly, calls to the Australian Poison Control Centre increased fivefold between 2004 and 2010, with cardiac events, hallucinations or seizures reported in $10 \%$ of cases. ${ }^{34}$ The US Food and Drug Administration has identified more than 30 deaths linked with energy drinks, based on adverse events reports between 2004 and 2012. ${ }^{35,36}$ In Canada, a newspaper investigation showed that serious side effects of energy drinks were reported to Health Canada by 35 Canadians between 2003 and 2012, as well as 3 deaths. ${ }^{37}$

Adverse event reports represent only a "small fraction" of adverse events associated with any product, owing to underreporting and other biases. ${ }^{38}$ Population-based surveys of energy drink consumers may be less susceptible to underreporting, because consumers are contacted proactively. A school-based study of seventh-grade students in Finland showed increased odds of headaches, sleeping problems and irritation among energy drink users. ${ }^{39}$ An Italian survey revealed that $45 \%$ of medical students reported adverse outcomes, including palpitations (35\%), insomnia (21\%) and irritability $(20 \%) .^{40}$ In an Australian study conducted among $12-$ to 18-year-olds, just over half of participants reported experiencing at least 1 physical symptom after consuming an energy drink, including racing heart (41\%), upset stomach $(28 \%)$, anxiety $(22 \%)$, tremors $(18 \%)$ and heart palpitations $(16 \%){ }^{41}$ Finally, a survey conducted in Poland showed that $29 \%$ of young athletes who reported consuming energy drinks reported a "health problem."

The current study sought to assess adverse events from energy drinks among a population-based sample of youth and young adults in Canada, including reports of seeking medical attention. Adverse events from coffee were also assessed for comparison, given that caffeine consumption from coffee has been used as the reference in risk assessments for energy drinks in Canada and elsewhere. ${ }^{43}$

\section{Methods}

\section{Setting}

Data were collected via self-completed Web-based surveys that took place between Nov. 6 and Dec. 22, 2015. Respondents were from all provinces, and surveys were completed in English or French.

\section{Design}

We recruited participants via email through the Legerweb consumer panel. The Legerweb panel has over 400000 active members, half of whom are sampled through probabilitybased methods (via telephone), with additional members recruited online and through word of mouth, social media and refer-a-friend programs. Email invitations (with a unique link) were sent to a random sample of panellists (after targeting for age criteria), primarily to those of known eligibility and supplemented with those of unknown eligibility; panellists known to be ineligible were not invited. Respondents aged 18-24 years were recruited directly, whereas those aged 12-17 years were recruited through their parents, and parental consent was obtained before youth accessed the survey. After eligibility screening, all respondents were provided with information about the study and were asked to provide consent before participating. Respondents received remuneration from Léger Marketing in accordance with their usual incentive structure, which includes points-based or monetary rewards (redeemed as cash or donated) as well as chances to win monthly prizes.

No personal identifiers were collected as part of this study.

\section{Sources of data/measures}

All respondents who had ever tried energy drinks (i.e., everconsumers) were asked, "Have you ever experienced any of the following after drinking an energy drink?," with an option to select all that applied from the following: "jolt and crash" episodes (increased alertness and energy followed by a sudden drop in energy), headache, jittery/shaking, difficulty sleeping, fast heartbeat, chest pain, nausea/vomiting/diarrhea, seizures, decreased sexual performance, dental pain, other (respondents were asked to specify) or none of the above. Respondents who selected "fast heartbeat," "chest pain" or "seizures" were asked 
a follow-up question to confirm how many times they had experienced the effect after consuming energy drinks, with the options "never," "once" or "more than once;" those who said "never" were excluded from estimates. Respondents who reported experiencing any adverse event were asked follow-up questions, including how many drinks they had consumed, what activities they had been participating in concurrently and whether they had sought or had considered seeking medical attention. Parallel questions were asked of those who had ever tried coffee.

We selected questionnaire items based on previous research where possible, although the items of interest noted above are novel. The survey used in the current study was based on a previous iteration (pilot-tested and fielded in 2014), with only minor changes, and was thoroughly tested for functionality and usability before data collection. The survey took about 20 minutes to complete and included questions eliciting sociodemographic information, a 24-hour recall of caffeinated products, items on energy drink use, perceptions, knowledge and marketing (Appendix 1, available at www.cmajopen.ca/content/6/1/E19/suppl/DC1). Additional methodological description is available in the technical report. $^{44}$

\section{Statistical analysis}

We constructed poststratification sample weights based on population estimates from the 2011 National Household Survey. ${ }^{45}$ Using the individual-level 2011 National Household Survey data set, we created sample probabilities based on weighted proportions for 40 demographic groups (each group being calculated as [ $n$ in current study/weighted $n$ in National Household Survey]): age group (12-14 yr, 15-17 yr, 18-19 yr, 20-24 yr) by sex and by region (British Columbia, Prairies, Ontario, Quebec, Atlantic). Weights were calculated as (1/sample probability) for each group and were applied to the current data set. We tested differences in the prevalence of adverse events for energy drinks and coffee using generalized estimating equations modelling. All estimates are weighted unless otherwise specified. We conducted analyses using SPSS version 23 (IBM).

\section{Ethics approval}

The study received ethics approval from the Office of Research Ethics at the University of Waterloo.

\section{Results}

\section{Sample}

A total of 37152 online panel members were sent an email invitation to the survey (20 614 members aged 18-24 yr and 16538 parents of youth aged $12-17 \mathrm{yr}$ ), of whom $3108(8.4 \%)$ accessed the survey link. A total of 2181 invitees (5.9\%) completed the survey; 291 others refused, 546 were classified as ineligible, and 90 were of unknown eligibility. All invitees who consented to participate in the survey completed it to the end (although some items may have been missing, as respondents could always choose "don't know" or "refuse to answer"). A total of 126 records were deleted: because of missing data on variables used for weighting in 22 cases, because the survey was completed outside the study time frame in 1 case and because of failure on a question checking data quality that asked for the current month in 103 cases. Thus, a total of 2055 surveys (5.5\% of all invitations sent) were retained for analysis.

Table 1 shows the demographic characteristics of the sample. A total of 1516 respondents (73.8\%) reported having ever consumed an energy drink, and $1741(84.7 \%)$ reported having ever consumed coffee (unweighted).

\section{Adverse events}

Overall, $41.5 \%$ of the 2055 respondents reported ever experiencing at least 1 adverse event from energy drinks, and 30.6\% reported ever experiencing at least 1 adverse event from coffee. The overall proportion who reported experiencing an adverse event was significantly higher with energy drinks than with coffee (odds ratio [OR] 1.63 [95\% confidence interval (CI) 1.46-1.81]). More than half (55.4\%) of respondents who reported ever consuming energy drinks reported at least 1 adverse event, compared to $36.0 \%$ of those who reported ever consuming coffee (OR 2.67 [95\% CI 2.01-2.56]). The proportions of ever-consumers who reported experiencing the various adverse events are shown in Table 2.

Most respondents who reported experiencing an adverse event from energy drinks had consumed less than the recommended maximum of 1 or 2 drinks (depending on the size of the container): $50.8 \%(n=421)$ reported having 1 drink, and $23.2 \%(n=1811), 2$ drinks. Similarly, most of those who reported experiencing an adverse event from coffee had consumed $1(43.0 \%[n=257])$ or $2(24.2 \%[n=152])$ beverages.

\section{Seeking medical attention}

A total of $1.2 \%(n=19)$ of energy drink consumers reported having sought medical help or having talked to a health care professional about an adverse event(s), most commonly for fast heartbeat, chest pain, headache, jitteriness or gastrointestinal effects. A further $1.8 \%(n=28)$ considered seeking medical attention. The corresponding proportions for coffee consumers were $0.7 \%(n=12)$ (most commonly for headache, difficulty sleeping, fast heartbeat or gastrointestinal effects) and $0.7 \%(n=12)$.

Energy drink consumers were significantly more likely than coffee consumers to report having sought or considered seeking medical attention for an adverse event (3.1\% v. $1.4 \%$ ) (OR 2.18 [95\% CI 1.39-3.41]).

\section{Concurrent activities}

Respondents who reported having experienced an adverse event were asked about other activities they had been participating in at the same time (Table 3). Although a substantial proportion had consumed alcohol, drugs/medications or other caffeinated products, or were participating in physical activity, nearly half $(48.6 \%)$ of those with adverse events from energy drinks and more than three-quarters (76.7\%) of those with adverse events from coffee reported none of these activities. 


\section{Table 1: Demographic characteristics of Canadian respondents aged $12-24$ years}

\begin{tabular}{|c|c|}
\hline Characteristic & $\begin{array}{l}\text { No. (\%) of respondents } \\
\text { (unweighted) } \\
n=2055\end{array}$ \\
\hline \multicolumn{2}{|l|}{ Sex } \\
\hline Female & $1016(49.4)$ \\
\hline Male & $1039(50.6)$ \\
\hline \multicolumn{2}{|l|}{ Age group, yr } \\
\hline $12-14$ & $401(19.5)$ \\
\hline $15-17$ & $621(30.2)$ \\
\hline $18-20$ & $336(16.4)$ \\
\hline $21-24$ & 697 (33.9) \\
\hline \multicolumn{2}{|l|}{ Language } \\
\hline English & $1240(60.3)$ \\
\hline French & 815 (39.6) \\
\hline \multicolumn{2}{|l|}{ Race/ethnicity* } \\
\hline White & $1513(73.6)$ \\
\hline Chinese & $92(4.5)$ \\
\hline South Asian & $88(4.3)$ \\
\hline Black & 65 (3.2) \\
\hline Aboriginal & $63(3.1)$ \\
\hline Other/mixed & $202(9.8)$ \\
\hline Don’t know/refused & $32(1.6)$ \\
\hline \multicolumn{2}{|l|}{ Province } \\
\hline British Columbia & $150(7.3)$ \\
\hline Alberta & $185(9.0)$ \\
\hline Saskatchewan & $27(1.3)$ \\
\hline Manitoba & $62(3.0)$ \\
\hline Ontario & $636(30.9)$ \\
\hline Quebec & $887(43.2)$ \\
\hline New Brunswick & $25(1.2)$ \\
\hline Nova Scotia & $59(2.9)$ \\
\hline Prince Edward Island & $12(0.6)$ \\
\hline Newfoundland and Labrador & $12(0.6)$ \\
\hline \multicolumn{2}{|c|}{$\begin{array}{l}\text { *Respondents could select all that applied from a list including the following: } \\
\text { white, Chinese, South Asian (e.g., East Indian, Pakistani, Sri Lankan), black, } \\
\text { Filipino, Latin American, Southeast Asian (e.g., Cambodian, Indonesian, } \\
\text { Laotian, Vietnamese), Arab, West Asian (e.g., Afghan, Iranian), Japanese, } \\
\text { Korean, other. A separate question asked about Aboriginal status. } \\
\text { Responses were combined and recoded as follows: Aboriginal includes all } \\
\text { those who said they were Aboriginal; white, Chinese, South Asian and black } \\
\text { are exclusive categories (i.e., only that race/ethnicity selected); and other/ } \\
\text { mixed includes all other races/ethnicities selected and all those who } \\
\text { selected more than } 1 \text { category. }\end{array}$} \\
\hline
\end{tabular}

\section{Interpretation}

The current findings suggest that about 4 in 10 respondents (including consumers and nonconsumers) have experienced an adverse event associated with energy drinks, including more than half of consumers. The prevalence of self-
Table 2: Proportions of ever-consumers of energy drinks and coffee who reported ever experiencing adverse events

\begin{tabular}{|c|c|c|}
\hline \multirow[b]{2}{*}{ Adverse event } & \multicolumn{2}{|c|}{ 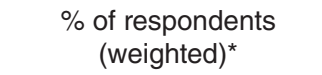 } \\
\hline & $\begin{array}{c}\text { Ever } \\
\text { consumed } \\
\text { energy } \\
\text { drinks } \\
n=1516\end{array}$ & $\begin{array}{c}\text { Ever } \\
\text { consumed } \\
\text { coffee } \\
n=1741\end{array}$ \\
\hline $\begin{array}{l}\text { "Jolt and crash" episodes } \\
\text { (increased alertness and energy } \\
\text { followed by sudden drop in } \\
\text { energy) }\end{array}$ & 22.5 & 9.7 \\
\hline Headache & 18.3 & 11.5 \\
\hline Jittery/shaking & 26.5 & 17.0 \\
\hline Difficulty sleeping & 24.1 & 16.5 \\
\hline Fast heartbeat & 24.7 & 10.5 \\
\hline Chest pain & 3.6 & 1.7 \\
\hline Nausea/vomiting/diarrhea & 5.1 & 5.1 \\
\hline Seizures & 0.2 & 0.2 \\
\hline Decreased sexual performance & 0.5 & 0.3 \\
\hline Dental pain & 1.8 & 0.8 \\
\hline Other & 0.8 & 1.5 \\
\hline None of the above & 39.7 & 60.8 \\
\hline Don't know/refuse to answer & 4.3 & 2.9 \\
\hline
\end{tabular}

Table 3: Concurrent activities of those who reported ever experiencing adverse events from energy drinks or coffee

\begin{tabular}{|c|c|c|}
\hline \multirow[b]{2}{*}{ Activity } & \multicolumn{2}{|c|}{$\%$ of respondents (weighted) } \\
\hline & $\begin{array}{l}\text { Energy drinks } \\
\quad n=865\end{array}$ & $\begin{array}{c}\text { Coffee } \\
n=607\end{array}$ \\
\hline Drinking alcohol & 22.5 & 3.2 \\
\hline $\begin{array}{l}\text { Participating in sports or } \\
\text { physical activity }\end{array}$ & 18.5 & 7.6 \\
\hline $\begin{array}{l}\text { Consuming other caffeinated } \\
\text { products }\end{array}$ & 10.6 & 6.0 \\
\hline Taking recreational drugs & 8.3 & 4.4 \\
\hline Taking medication(s) & 6.4 & 5.6 \\
\hline None of these & 48.6 & 76.7 \\
\hline Don't know/refuse to answer & 4.1 & 2.9 \\
\hline
\end{tabular}

reported adverse events in the current sample is similar to that in population-based surveys of youth in Australia. ${ }^{41} \mathrm{We}$ are unaware of any population-based studies conducted among adults; however, our findings are generally consistent with the interpretation that youth may be more vulnerable to the effects of caffeine than adults, potentially owing to 
smaller body size as well as lower levels of pharmacological tolerance to the effects of caffeine because of lower habitual intake. $^{16}$

Consistent with recent reviews, ${ }^{15,16}$ the adverse events most commonly reported by our respondents affected the cardiovascular and neurologic systems. The most common selfreported serious adverse events were fast heartbeat, difficulty sleeping, headache, nausea/vomiting/diarrhea and chest pain. Although relatively few respondents reported experiencing seizures following energy drink consumption, a previous review showed an association between seizures and energy drinks. ${ }^{15}$ The types of adverse events are also consistent with data contained in the Canada Vigilance Adverse Reaction Online Database, Health Canada's postmarket surveillance program that collects and assesses reports of suspected adverse reactions to health products marketed in Canada ${ }^{46}$ (Appendix 2, available at www.cmajopen.ca/content/6/1/E19/ suppl/DC1).

The current study suggests that adverse effects - including serious adverse events that prompted people to seek or to consider seeking medical assistance - are more prevalent with energy drinks than with coffee. The comparisons between energy drinks and coffee are notable, given that hazard assessments for energy drinks have been based primarily on consumption of caffeine from coffee and similar beverages. ${ }^{45}$ The energy drink industry has also relied on the safety of other caffeinated beverages, such as coffee, to establish the safety of energy drinks when assessing the potential health effects of their products. ${ }^{47,48}$ However, the current findings suggest that adverse outcomes from energy drinks exceed the direct effects of caffeine alone. This is consistent with the Canada Vigilance Adverse Reaction Online Database, which indicates substantially higher numbers of adverse reaction reports for energy drinks than for coffee between 1999 and 2013.48

It is unclear to what extent adverse events from energy drinks are due to caffeine, other product constituents or an interaction between the two. Common stimulants in energy drinks, such as taurine and guarana extracts, may have independent effects - for example, taurine can have deleterious effects on sodium channels and can cause arrhythmias - and may also potentiate the effects of caffeine..$^{15,49}$ For this reason, it has been suggested that the adverse effects of energy drinks should not simply be generalized from caffeine, and energy drinks should be considered a "novel" exposure. ${ }^{50}$ Coingestion of energy drinks with alcohol and other drugs may also increase the effects of caffeine. ${ }^{51}$ As in previous studies, ${ }^{15}$ a substantial number of respondents in the current study reported drinking alcohol and/or using other drugs during the occasion of the adverse event. The association between energy drinks and high-risk alcohol consumption has been well established. ${ }^{52}$ However, coingestion with other substances accounted for only a minority of respondents who reported an adverse event in our study. It is notable that almost one-fifth of respondents who reported an adverse event also reported concurrently engaging in physical activity. According to Health Canada, "the consumption of [caffeinated energy drinks] within the context of sport performance is not recommended as their intake could lead to serious adverse effects, especially when used for purposes of hydration." ${ }^{10}$ Despite this, sporting activities are among the most common themes in energy drink advertising, and several studies suggest that energy drinks are being consumed by youth to improve their sports performance. . $^{6,53-56}$

\section{Strengths and limitations}

The accuracy of adverse events can be difficult to establish with any methodology. Although such surveys have limitations, the use of a population-based Web survey is a strength compared with adverse event databases, which require proactive reporting and are known to underrepresent the number of adverse events. The current study also included measures on concurrent activities and comparisons with adverse events from coffee, which also represents a strength. Overreporting, including reporting of health events that are unrelated to energy drinks, is a possibility in the current study. Measures were taken to identify "false" reports, including follow-up questions about serious adverse events, and a question to test general data quality was included. Underreporting is also possible, owing to a failure to link adverse effects with energy drink consumption. It is also possible that respondents misclassified some of the beverages they consumed. However, to minimize this risk, we prefaced questions on energy drink consumption with, "We would like to ask you some more questions about energy drinks. Popular brands include Red Bull, Monster, Rockstar, NOS, Amp and Full Throttle, but there are others. DO NOT include sports drinks, such as Gatorade or Powerade." The caffeine content in energy drinks and coffee varies depending on the product and size, so it was not possible to estimate precisely how much caffeine a person had consumed when experiencing adverse effects, although the guidance for not exceeding 1-2 drinks per day was used as a conservative estimate.

Finally, the sample was drawn from a commercial panel where not all respondents were recruited through probability-based methods. The response rate of the survey was relatively low. In addition, some groups (e.g., Quebec residents) were overrepresented in the sample. However, we used poststratification weights to ensure representative distributions of age, sex and geographic region in the analysis. As with all online surveys, the population completing the survey may not represent the total target population (in this case, Canadians aged 12-24 yr), although we do not expect people who had experienced an adverse effect from energy drinks to be more or less likely to be a part of an online consumer panel or to have completed the survey (note that initial survey invitations did not specify the survey topic). Indeed, the prevalence of energy drink consumption in the current study was similar to or slightly higher than that in other, larger provincial and national studies. ${ }^{57-59}$ The effects of any sample bias are unclear; however, failure to adequately represent "at-risk" youth in the sample would lead to lower estimates of prevalence and, possibly, lower estimates of adverse outcomes. In addition, all adverse effects are reported as proportions 
among energy drink users, so even if the current study underor overrepresented energy drink users in this age group, the proportion of users experiencing adverse outcomes would not be expected to differ.

\section{Conclusion}

The current findings are consistent with those of Health Canada's Expert Panel on Caffeinated Energy Drinks, which concluded that, although the probability of serious adverse events is low, given the high volume of use, the risk of adverse events "is considered to be a public health issue." 5 Public health authorities may be warranted in considering additional regulations on energy drinks, including minimum age restrictions and enhanced health warnings. To assess the prevalence and nature of adverse events from energy drinks, broader consumer surveys should be conducted, in addition to monitoring through current consumer reporting mechanisms.

\section{References}

1. Higgins JP, Tuttle TD, Higgins CL. Energy beverages: content and safety. Mayo Clin Proc 2010;85:1033-41.

2. Arria AM, O'Brien MC. The high risk of energy drinks. FAMA 2011;305: 600-1.

3. Macdonald N, Stanbrook M, Hébert PC. "Caffeinating" children and youth. CMA7 2010;182:1597.

4. Institute of Medicine. Caffeine in food and dietary supplements: examining safety: workshop summary. Washington: National Academies Press; 2014.

5. MacDonald N, Hamilton R, Malloy P, et al. Report by the Expert Panel on Caffeinated Energy Drinks. Ottawa: Health Canada; 2010. Available: www. hc-sc.gc.ca/dhp-mps/alt_formats/pdf/prodnatur/activit/groupe-expert-panel/ report_rapport-eng.pdf (accessed 2016 Aug. 17).

6. Seifert SM, Schaechter JL, Hershorin ER, et al. Health effects of energy drinks on children, adolescents, and young adults. Pediatrics 2011;127:511-28

7. Caffeine in food. Ottawa: Health Canada; [modified 2012]. Available: www. hc-sc.gc.ca/fn-an/securit/addit/caf/food-caf-aliments-eng.php (accessed 2016 Aug. 17).

8. Select Committee on GRAS Substances (SCOGS) opinion: caffeine. Silver Spring (MD): US Food and Drug Administration; 1978. Available: www.fda. gov/Food/IngredientsPackagingLabeling/GRAS/SCOGS/ucm256650.htm (accessed 2014 Dec. 19).

9. Nawrot P, Jordan S, Eastwood J, et al. Effects of caffeine on human health. Food Addit Contam 2003;20:1-30.

10. Category specific guidance for temporary marketing authorization - caffeinated energy drinks. Ottawa: Food Directorate, Health Products and Food Branch, Health Canada; [modified 2014]. Available: www.hc-sc.gc.ca/fn-an/ legislation/guide-ld/guidance-caf-drink-boiss-tma-amt-eng.php (accessed 2015 Apr. 10).

11. Energy Drinks Marketing Code. Toronto: Canadian Beverage Association; 2013. Available: www.canadianbeverage.ca/wp-content/uploads/2013/12/CBA -Energy-drinks-Code-FINAL-English.pdf (accessed 2018 Jan. 2).

12. Sherwood J. Energy drinks: beverage industry response. CMAf 2010;182: 1647-8.

13. Position statement: energy drinks. Fredericton (NB): Office of the Chief Medical Officer of Health; 2014. Available: www2.gnb.ca/content/dam/gnb/Departments/h-s/ $\mathrm{pdf} / \mathrm{en} /$ HealthyPeople/Dialogue/PositionStatementEnergyDrinks.pdf (accessed 2018 Jan. 2).

14. Committee on Nutrition and the Council on Sports Medicine and Fitness. Sports drinks and energy drinks for children and adolescents: Are they appropriate? Pediatrics 2011;127:1182-9.

15. Ali F, Rehman H, Babayan Z, et al. Energy drinks and their adverse health effects: a systematic review of the current evidence. Postgrad Med 2015;127:308-22.

16. Harris JL, Munsell CR. Energy drinks and adolescents: What's the harm? Nutr Rev 2015;73:247-57.

17. Svatikova A, Covassin N, Somers KR, et al. A randomized trial of cardiovascular responses to energy drink consumption in healthy adults. $7 A M A 2015$; 314:2079-82.

18. Goldfarb M, Tellier C, Thanassoulis G. Review of published cases of adverse cardiovascular events after ingestion of energy drinks. Am 7 Cardiol 2014;113: 168-72.

19. Dikici S, Saritas A, Besir FH, et al. Do energy drinks cause epileptic seizure and ischemic stroke? Am f Emerg Med 2013;31:274.e1-4.

20. Iyadurai SJ, Chung SS. New-onset seizures in adults: possible association with consumption of popular energy drinks. Epilepsy Behav 2007;10:504-8.
21. Ferlazzo E, Aguglia U. Energy drinks and seizures: What is the link? Epilepsy Behav 2012;24:151.

22. Calabrò RS, Italiano D, Gervasi G, et al. Single tonic-clonic seizure after energy drink abuse. Epilepsy Behav 2012;23:384-5.

23. Dikici S, Saritas A, Kilinc S, et al. Does an energy drink cause a transient ischemic attack? Am 7 Emerg Med 2015;33:129.e5-6.

24. Rottlaender D, Motloch LJ, Reda S, et al. Cardiac arrest due to long QT syndrome associated with excessive consumption of energy drinks. Int 7 Cardiol 2012;158:e51-2.

25. Rajbhandary A, Pokhrel K, Fatima U. The real monster: energy drinks may cause of fatal arrhythmia [sic] [abstract 1254]. Crit Care Med 2013;41(Suppl 1):B1-16, A1-A377. Available: http://journals.lww.com/ccmjournal/Abstract/ 2013/12001/1254_The_Real_Monster_Energy_drinks_may_cause.1204. aspx (accessed 2014 Mar. 21).

26. Sattari M, Sattari A, Kazory A. Energy drink consumption and cardiac complications: a case for caution. 7 Addict Med 2016;10:280-2.

27. Sanchis-Gomar F, Pareja-Galeano H, Cervellin G, et al. Energy drink overconsumption in adolescents: implications for arrhythmias and other cardiovascular events. Can 7 Cardiol 2015;31:572-5.

28. Jackson DA, Cotter BV, Merchant RC, et al. Behavioral and physiologic adverse effects in adolescent and young adult emergency department patients reporting use of energy drinks and caffeine. Clin Toxicol (Phila) 2013;51:557-65.

29. Nordt SP, Vilke GM, Clark RF, et al. Energy drink use and adverse effects among emergency department patients. 7 Community Health 2012;37:976-81.

30. Nordt SP, Claudius I, Rangan C, et al. Reasons for energy drink use and reported adverse effects among adolescent emergency department patients. Pediatr Emerg Care 2017;33:770-3.

31. Busuttil M, Willoughby S. A survey of energy drink consumption among young patients presenting to the emergency department with the symptom of palpitations. Int 7 Cardiol 2016;204:55-6.

32. Update on emergency department visits involving energy drinks: a continuing public health concern. The Drug Abuse Warning Network (DAWN) Report 2013 Jan. 10. Available: www.samhsa.gov/data/2k13/DAWN126/sr126-energy -drinks-use.pdf (accessed 2013 Mar. 13).

33. Seifert SM, Seifert SA, Schaechter JL, et al. An analysis of energy-drink toxicity in the National Poison Data System. Clin Toxicol (Phila) 2013;51:566-74.

34. Gunja N, Brown JA. Energy drinks: health risks and toxicity. Med f Aust 2012; 196:46-9.

35. Adverse event reports allegedly related to Red Bull. Silver Spring (MD): US Food and Drug Administration; 2012. Available: www.fda.gov/downloads/AboutFDA/ CentersOffices/OfficeofFoods/CFSAN/CFSANFOIAElectronicReadingRoom/ UCM328525.pdf (accessed 2015 May 15).

36. Adverse event reports allegedly related to 5-Hour Energy, Monster and Rockstar. Silver Spring (MD): US Food and Drug Administration; 2012. Available: www.fda.gov/downloads/AboutFDA/CentersOffices/OfficeofFoods/CFSAN/ CFSANFOIAElectronicReadingRoom/UCM328270.pdf (accessed 2015 May $15)$.

37. Bruser D. Energy drinks suspected to have caused deaths of 3 Canadians. Toronto Star 2012 Nov. 18. Available: https://www.thestar.com/news/canada/2012/11/18/ energy_drinks_suspected_to_have_caused_deaths_of_3_canadians.html (accessed 2018 Jan. 2).

38. Energy "drinks" and supplements: investigations of adverse events reports. Silver Spring (MD): US Food and Drug Administration; [updated 2015]. Available: www.fda.gov/Food/NewsEvents/ucm328536.htm (accessed 2016 Aug. 17).

39. Koivusilta L, Kuoppamäki H, Rimpelä A. Energy drink consumption, health complaints and late bedtime among young adolescents. Int 7 Public Health 2016;61:299-306.

40. Casuccio A, Bonanno V, Catalano R, et al. Knowledge, attitudes, and practices on energy drink consumption and adverse events in a cohort of medical students. 7 Addict Dis 2015;34:274-83.

41. Costa BM, Hayley A, Miller P. Adolescent energy drink consumption: an Australian perspective. Appetite 2016;105:638-42.

42. Nowak D, Jasionowski A. Analysis of consumption of energy drinks by a group of adolescent athletes. Int 7 Environ Res Public Health 2016;13:E768.

43. Rotstein J, Barber J, Strowbridge C, et al. Energy drinks: an assessment of the potential health risks in the Canadian context. Int Food Risk Analysis 7 2013;3: $1-29$.

44. Reid J, Hammond D. Evaluating the impact of Canada's caffeinated energy drink policy among youth and young adults. Waterloo (ON): University of Waterloo; 2016. Available: http://davidhammond.ca/wp-content/uploads/ 2014/12/2015-CED-Technical-Report-Final.pdf (accessed 2018 Jan. 2).

45. National Household Survey. Ottawa: Statistics Canada; 2011. Available: www12.statcan.gc.ca/nhs-enm/2011/dp-pd/prof/index.cfm?Lang=E (accessed 2018 Jan. 2).

46. Canada Vigilance Program. Ottawa: Health Canada; 2016. Available: www. hc-sc.gc.ca/dhp-mps/medeff/vigilance-eng.php (accessed 2018 Jan. 2).

47. Energy drink information. Toronto: Canadian Beverage Association; 2015 Available: http://energydrinkinformation.ca/ (accessed 2018 Jan. 2).

48. CBA responds to New Brunswick $\mathrm{CMOH}$ statement on energy drinks [press release]. Toronto: Canadian Beverage Association; 2015 Apr. 1. Available: www. newswire.ca/news-releases/cba-responds-to-new-brunswick-cmoh-statement-on -energy-drinks-517419701.html (accessed 2018 Jan. 2). 
49. Satoh H. Cardiac actions of taurine as a modulator of the ion channels. $A d v$ Exp Med Biol 1998;442:121-8.

50. Wolk BJ, Ganetsky M, Babu KM. Toxicity of energy drinks. Curr Opin Pediatr 2012;24:243-51.

51. George J, Murphy T, Roberts R, et al. Influence of alcohol and caffeine consumption on caffeine elimination. Clin Exp Pharmacol Physiol 1986;13:731-6.

52. Marczinski CA, Fillmore MT. Energy drinks mixed with alcohol: What are the risks? Nutr Rev 2014;72(Suppl 1):98-107.

53. Reid JL, MCrory C, White CM, et al. Consumption of caffeinated energy drinks among youth and young adults in Canada. Prev Med Rep 2017;5:65-70.

54. Duchan E, Patel ND, Feucht C. Energy drinks: a review of use and safety for athletes. Phys Sportsmed 2010;38:171-9.

55. Buxton C, Hagan JE. A survey of energy drinks consumption practices among student-athletes in Ghana: lessons for developing health education intervention programmes. 7 Int Soc Sports Nutr 2012;9:9.

56. Paddock R. Energy drinks' effects on student-athletes and implications for athletic departments. Sport 7 2008;11: unpaginated.

57. Reid JL, Hammond D, McCrory C, et al. Use of caffeinated energy drinks among secondary school students in Ontario: prevalence and correlates of using energy drinks and mixing with alcohol. Can 7 Public Health 2015;106:e101-8.

58. Paglia-Boak A, Hamilton HA, Adlaf EM, et al. Drug use among Ontario students, 1977-2013: detailed OSDUHS findings. CAMH Research Document Series No. 36. Toronto: Centre for Addiction and Mental Health; 2013. Available: www. camh.ca/en/research/news_and_publications/ontario-student-drug-use-and -health-survey/Documents/2013\%20OSDUHS\%20Docs/2013OSDUHS_ Detailed_DrugUseReport.pdf (accessed 2018 Jan. 2).

59. Summary of results: Canadian Student Tobacco, Alcohol and Drugs Survey 2014/15. Ottawa: Health Canada; [modified 2016]. Available: https://www.canada. $\mathrm{ca} / \mathrm{en} /$ health-canada/services/canadian-student-tobacco-alcohol-drugs-survey/2014 -2015-summary.html (accessed 2018 Jan. 2).

Affiliations: School of Public Health and Health Systems (Hammond, Reid, Zukowski), University of Waterloo, Waterloo, Ont.; School of Nursing (Zukowski), McMaster University, Hamilton, Ont.

Contributors: David Hammond conceived of and designed the study and interpreted the data. Jessica Reid managed data collection and conducted the data analysis. Sara Zukowski collected the data and summarized the results of the adverse events database analysis. All of the authors contributed to drafting and revising the manuscript, gave final approval of the version to be published and agreed to be accountable for all aspects of the work.

Funding: This project was funded by a Canadian Institutes for Health Research (CIHR) Operating Grant. Additional support was provided by a CIHR New Investigator Award, a Canadian Cancer Society Research Institute Junior Investigator Research Award and a CIHR-Public Health Agency of Canada Applied Chair in Public Health to David Hammond.

Acknowledgement: The authors thank Pete Driezen for consulting on aspects of the data analysis.

Supplemental information: For reviewer comments and the original submission of this manuscript, please see www.cmajopen.ca/content/6/1/ E19/suppl/DC1. 